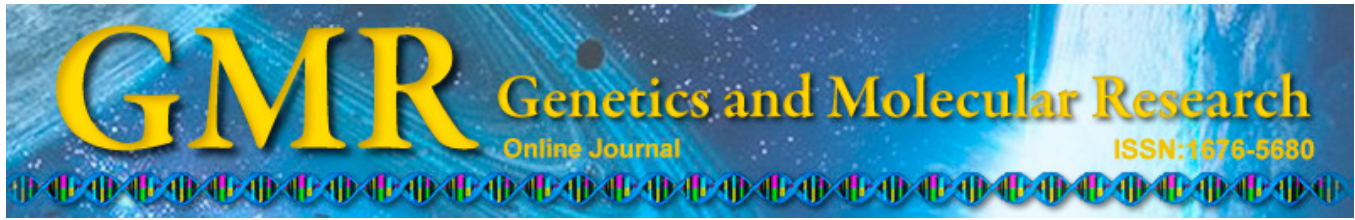

\title{
Attenuated mRNA expression of lipid metabolism genes in primary hepatocytes following lipopolysaccharide treatment in dairy cows
}

\author{
Y.Y. Wang*, H.P. Li*, X.J. Wang, Q.D. Jiang, J. Geng, L.F. Wang, \\ Y.J. Guo, W.F. Lu, H.S. Zhu and G.Y. Yang
}

Key Laboratory of Animal Biochemistry and Nutrition, Ministry of Agriculture, Henan Agricultural University, Zhengzhou, Henan, China

*These authors contributed equally to this study. Corresponding authors: H.S. Zhu / G.Y. Yang

E-mail: wangyueying2008@126.com

Genet. Mol. Res. 14 (2): 3718-3728 (2015)

Received May 13, 2014

Accepted October 23, 2014

Published April 17, 2015

DOI http://dx.doi.org/10.4238/2015.April.17.21

\begin{abstract}
The influence of ruminal acidosis on ruminal microbiology and metabolite production has received considerable attention, but little is known regarding the systemic manifestations that arise from ruminal acidosis. Lipopolysaccharide (LPS) is released in the gastrointestinal tract upon ingestion of high-grain or high-fat diets, and it has been implicated in the etiology of multiple energy- and lipid-related metabolic disturbances in ruminants. The liver plays a crucial role in the acute phase response to intruding pathogens. The effect of blood LPS in subacute ruminal acidosis on lipid metabolism in the liver has not been established. In this study, cell cultures were photographed using an inverted microscope. We observed that hepatocytes changed their morphologies from irregular triangle to circular (contraction) shapes; the number of contracted cells increased with the increasing LPS doses. This suggests that LPS can
\end{abstract}


promote cell contraction and take off the wall, ultimately leading to cell apoptosis. With changes in LPS exposure, hepatocyte number also changes. We explored lipid metabolism in the liver using quantitative reverse transcription-polymerase chain reaction to detect the expression of key lipid metabolism enzymes in hepatocytes. We found that Toll-like receptor 4 signaling pathway mediated by LPS could attenuate mRNA expression of fatty acid synthesis genes and increase the expression of fatty acid transport genes in primary hepatocytes following LPS treatment in dairy cows.

Key words: Dairy cow; Lipid metabolism genes; Lipopolysaccharide; Primary hepatocyte; Toll-like receptor 4 signaling pathway

\section{INTRODUCTION}

Current feeding practices in high-producing beef and dairy cattle use highly fermentable diets to increase growth rates and milk production. However, because of microbial disturbances, these factors predispose cattle to digestive disorders such as ruminal acidosis (Khafipour et al., 2009). Field studies in Europe and the USA have estimated that $11-19 \%$ of early lactation and $18-26 \%$ of mid-lactation dairy cows have subacute ruminal acidosis (SARA) (Enemark, 2008). SARA can promote health disorders such as diarrhea, laminitis, liver abscesses, increased bacterial endotoxin levels, and inflammation characterized by increases in acute-phase proteins (Plaizier et al., 2008). The liver has several vital functions in metabolism, hormone synthesis, detoxification, and regulation of blood glucose levels to ensure homeostasis in the entire body. In addition, the liver plays a crucial role in the acute phase response to intruding pathogens (Tacke et al., 2009).

Lipopolysaccharide (LPS) and/or the low-pH rumen conditions may increase the permeability of the gut to LPS, which can trigger systemic inflammation (Chin et al., 2006). The influence of ruminal acidosis on ruminal microbiology and metabolite production has received considerable attention, but less is known regarding systemic manifestations that arise from ruminal acidosis (Brown et al., 2000). It has been increasingly recognized that LPS stimulates the release of proinflammatory cytokines, such as tumor necrosis factor (TNF)- $\alpha$, interleukin (IL)-1, and IL-6, by liver macrophages, which in turn activate hepatocytic receptors and initiate the synthesis of acute phase proteins (Sweet and Hume, 1996). LPS also modulates lipid metabolism in different body tissues. For example, previous studies identified the suppressive effects of LPS on key enzymes related to de novo fatty acid (FA) synthesis such as FA synthase (FAS) and acetyl-coenzyme A carboxylase (ACAC) (Pekala et al., 1983; Lopez-Soriano and Williamson, 1994) in the mammary glands and down-regulation of lipoprotein lipase activity (Khovidhunkit et al., 2004). The latter enzyme plays a key role in the clearing of circulating triglyceride-rich chylomicrons and very low-density lipoprotein (VLDL) as a host defense mechanism to decrease LPS toxicity (Feingold et al., 1992) and is involved in the uptake of FA for incorporation into milk fat (Merkel et al., 2002).

Recently, the LPS released in the gastrointestinal tract during feeding of high-grain or high-fat diets has been implicated in the etiology of multiple energy- and lipid-related metabolic disturbances in ruminants (Andersen, 2003; Ametaj et al., 2005), rodents, and humans (Cani et al., 2007; Amar et al., 2008). Nevertheless, the effect of blood LPS in SARA on lipid 
metabolism in the liver has not yet been established. Obtaining RNA to study transcripts of enzymes involved in lipid metabolism from the liver of a lactating beef cow is difficult because the process requires either liver tissue dissection or biopsy; the latter can be costly and potentially injurious to both the animal and the technician. In the current study, we examined lipid metabolism in the liver by using quantitative real-time polymerase chain reaction (PCR) to detect the expression of key lipid metabolism enzymes in hepatocytes.

\section{MATERIAL AND METHODS}

\section{Hepatocyte culture}

Primary hepatocytes were isolated from liver of male Holstein calves by collagenase perfusion. Hepatocytes then were seeded on collagen-coated plates and cultured in Dulbecco's modified Eagle's medium (DMEM; Gibco, Grand Island, NY, USA) supplemented with 10\% fetal bovine serum (Gibco) and the antibiotic antimycotic (Sigma, St. Louis, MO, USA) in a humidified atmosphere with $5 \% \mathrm{CO}_{2}$ at $37^{\circ} \mathrm{C}\left(\mathrm{MCO}-5 \mathrm{AC} \mathrm{CO}_{2}\right.$ incubator; SANYO, Tokyo, Japan). After attachment, cells were cultured in medium supplemented with LPS to analyze the effect of LPS on the expression of key lipid metabolism enzymes in primary hepatocytes.

\section{Experimental treatments}

LPS from Escherichia coli was obtained from Sigma. Cells were seeded on 12-well plates at a density of approximately $10^{5}$ cells $/ \mathrm{cm}^{2}$ and cultivated in $2 \mathrm{~mL} /$ well DMEM at $37^{\circ} \mathrm{C}$. The cells were treated with $0,50,75,100,250$, and $500 \mathrm{ng} / \mathrm{mL}$ LPS alone for $24 \mathrm{~h}$ and with $100 \mathrm{ng} / \mathrm{mL}$ LPS alone for $0,3,6,9,12$, and $24 \mathrm{~h}$. Cell cultures were observed and photographed using an inverted microscope.

\section{RNA extraction, reverse transcription, and reverse transcription-PCR}

Total RNA was extracted from cultured cells using TRIzol (Gibco) according to manufacturer instructions. cDNA was prepared using a reverse transcriptase kit (Takara, Shiga, Japan). The primers used for specific bovine genes [Toll-like receptor 4 (TLR4), myeloid differentiation factor 88 (MyD88), TNF receptor-associated factor 6 (TRAF6), IL-1 receptorassociated kinase 4 (IRAK4), nuclear factor $\kappa B(\mathrm{NF}-\kappa \mathrm{B})$; sterol regulatory element binding protein (SREBP), liver X receptor $\alpha(\mathrm{LXR} \alpha), \mathrm{LXR} \beta, \mathrm{FAS}$; stearoyl-CoA desaturase (SCD); ACAC $\alpha(A C A C \alpha)$; VLDL receptor (VLDLR); and glyceraldehyde-3-phosphate dehydrogenase (GAPDH)] were determined using the Primer Premier ${ }^{\mathrm{TM}}$ Version 5.0 software (PREMIER Biosoft, Palo Alto, CA, USA) and evaluated through BLASTs. All primers were synthesized by Shanghai Sangon Biological Engineering Technology \& Services Co. Ltd. (Shanghai, China). The sequences of primers used for PCR are shown in Table 1.

Real-time fluorescence PCR was performed using a SYBR Green PCR Kit (Takara) and a PCR Instrument (Eppendorf Mastercycler ep Realplex, Hamburg, Germany) in a 10$\mu \mathrm{L}$ volume. Each reaction tube contained $1.25 \mu \mathrm{L}$ cDNA template, $5 \mu \mathrm{L}$ SYBR Green PCR MasterMix, $0.1 \mu \mathrm{L}$ of each primer $(20 \mu \mathrm{M})$ and $3.55 \mu \mathrm{L} \mathrm{H}_{2} \mathrm{O}$. $\mathrm{H}_{2} \mathrm{O}$ without a cDNA template was used as a negative control. The GAPDH gene as an internal reference and the target genes were amplified from each sample at the same time. Each sample was analyzed in triplicate. 
Reverse transcription-PCR analysis was performed using the comparative CT method. The following PCR conditions were used: $95^{\circ} \mathrm{C}$ for $2 \mathrm{~min}$ and 40 cycles of $95^{\circ} \mathrm{C}$ for $15 \mathrm{~s}$ and $60^{\circ} \mathrm{C}$ for $20 \mathrm{~s}, 72^{\circ} \mathrm{C}$ for $20 \mathrm{~s}$.

\begin{tabular}{|c|c|c|}
\hline Gene & Primers & Accession No. \\
\hline TLR4 & $\begin{array}{l}\text { F: 5'-GCTGGACCTGAGCTTTAACTACCTG-3' } \\
\text { R: 5'-AGGTGGTTTAGGCCCTGAAATG-3' }\end{array}$ & NM_174198 \\
\hline MyD88 & $\begin{array}{l}\text { F: 5'-GAAGCTTGTGGGCACATGGA-3' } \\
\text { R: 5'-ATGCCTGTATGTCTGTGCGTGAG-3' }\end{array}$ & NM_001014382 \\
\hline TRAF6 & $\begin{array}{l}\text { F: 5'-GTGCTGTATCAATGGCATTTGAAG-3' } \\
\text { R: 5'-TGAACGTGCATGGGACTGG-3' }\end{array}$ & NM_001034661 \\
\hline IRAK4 & $\begin{array}{l}\text { F: 5'-GCTGTGGATGAACACCGTGAA-3' } \\
\text { R: 5'-GCAGACACTGACTGGCAACAGAG-3' }\end{array}$ & NM_001075998 \\
\hline $\mathrm{NF}-\kappa \mathrm{B}$ & $\begin{array}{l}\text { F: 5'-AAGCCGGTTCCAAATTCCA-3' } \\
\text { R: 5'-GCTTGAGGGCCATAAGGATCTTC-3' }\end{array}$ & NM_001102553.1 \\
\hline SREBP & $\begin{array}{l}\text { F: 5'-AGCCTGGCAATGTGTGAGAA-3' } \\
\text { R: 5'-ACACAGGAGCAGCTGCAAG-3' }\end{array}$ & NM_001113302 \\
\hline $\operatorname{LXR} \alpha$ & $\begin{array}{l}\text { F: 5'-GGAGGTACAACCCTGGAAGTGAGA-3' } \\
\text { R: 5'-TGGCAATGAGCAAGGCAAAC-3' }\end{array}$ & NM_001014861 \\
\hline LXR $\beta$ & $\begin{array}{l}\text { F: 5'-TTGCAGCTCGGTCGTGAAG-3' } \\
\text { R: 5'-GATGCACTCAGTCTCGTGGTTGTAG-3' }\end{array}$ & NM_001014883 \\
\hline FAS & $\begin{array}{l}\text { F: 5'-AGGACCTCGTGAAGGCTGTGA-3' } \\
\text { R: 5'-CCAAGGTCTGAAAGCGAGCTG-3' }\end{array}$ & NM_001012669 \\
\hline SCD & $\begin{array}{l}\text { F: 5'-TGATGGCTACTGCGGTCCAA-3' } \\
\text { R: 5'-GAGACTCTGGAGGCCAAGTGAAAG-3' }\end{array}$ & NM_173959 \\
\hline $\mathrm{ACAC} \alpha$ & $\begin{array}{l}\text { F: 5'-GCATCCAGATCATGCACAACA-3' } \\
\text { R: 5'-ATTGGATCCTTGGAGTTCAGGAG-3' }\end{array}$ & NM_174224 \\
\hline VLDLR & $\begin{array}{l}\text { F: 5'-CTCGGAGCTGGCCACTCTAGTTA-3' } \\
\text { R: 5'-GCTGGCAGGCAGAGGTATTCA-3' }\end{array}$ & NM_174489 \\
\hline GAPDH & $\begin{array}{l}\text { F: 5'-GATGGTGAAGGTCGGAGTGAAC-3' } \\
\text { R: 5'-GTCATTGATGGCGACGATGT-3' }\end{array}$ & NM_001034034 \\
\hline
\end{tabular}

\section{Statistical analysis}

All results are reported as means \pm standard deviation and were analyzed using the Statistical Package for the Social Sciences (SPSS Inc., Chicago, IL, USA) statistical software (version 13.0). Differences among groups were compared using one-way analysis of variance. Significance was set at $\mathrm{P}<0.05$ in two-tailed testing.

\section{RESULTS}

\section{Hepatocyte morphology changes following LPS treatment}

Cell cultures were photographed using an inverted microscope. The results are shown in Figures 1 and 2. The results showed that hepatocytes changed from an irregular triangle shape to a circular shape (contraction), and the contracted cell number showed increasing trend with the increasing doses of LPS. This suggests that LPS can promote cell contraction and take off the wall, ultimately leading to cell apoptosis. The time of LPS action and the number of hepatocytes also changed. LPS supplementation did not result in hepatocyte shrinkage or apoptosis from 3-9 $\mathrm{h}$ after treatment. Hepatocyte shrinkage increased from 12-24 h; apoptosis increased. Additionally, irregularly shaped triangular cells gradually changed their shape to the fusiform, long rod, and circular. This suggests that LPS promotes hepatocyte apoptosis. 


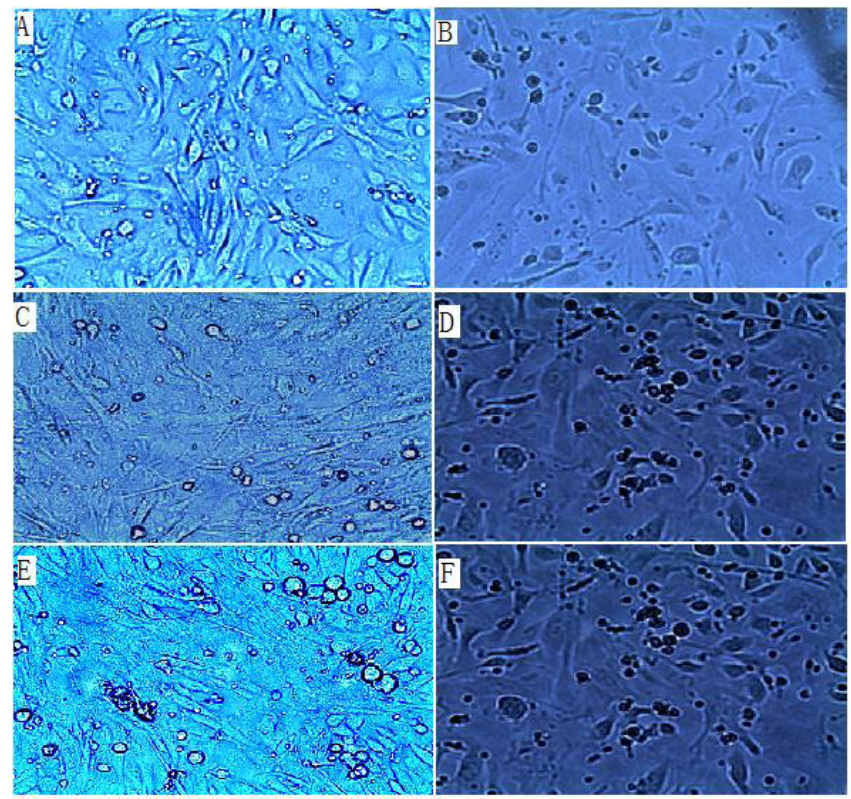

Figure 1. Dose-dependent effect of LPS on hepatocyte morphology. A., B., C., D., E., and F. denote hepatocytes treated with $0,50,75,100,250,500 \mathrm{ng} / \mathrm{mL}$ LPS, respectively, after $24 \mathrm{~h}$.

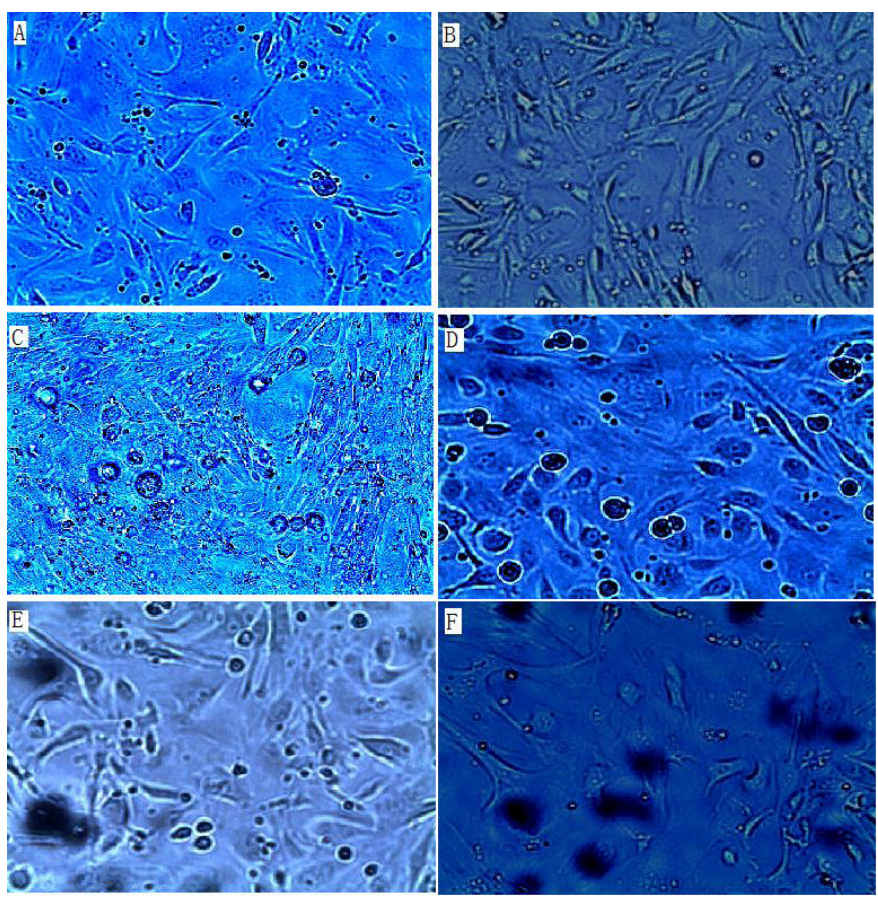

Figure 2. Time-dependent effect of LPS on hepatocyte morphology. A., B., C., D., E., and F. denote hepatocytes treated with $100 \mathrm{ng} / \mathrm{mL}$ LPS after 0, 3, 6, 9, 12, and $24 \mathrm{~h}$. 


\section{Effects of LPS on TLR4 signaling molecule gene expression in hepatocytes}

As shown in Figures 3 and 4,TLR4, NF- $k B$, IRAK4, MyD88, and TRAF6 mRNA increased in primary hepatocytes after LPS treatment. The effect of LPS on the expression of these genes depended on the dose and time after treatment. Thus, LPS can influence the TLR4 signaling molecule gene expression.

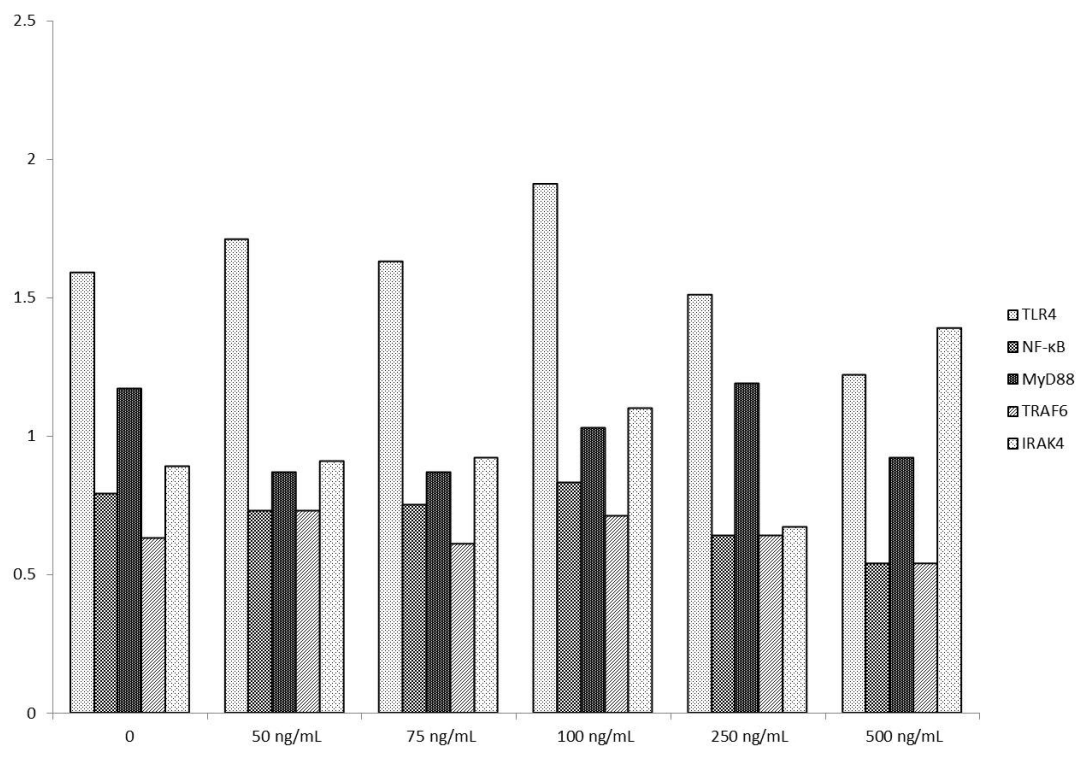

Figure 3. Dose-dependent effect of LPS on TLR4 signal molecule expression in hepatocytes.

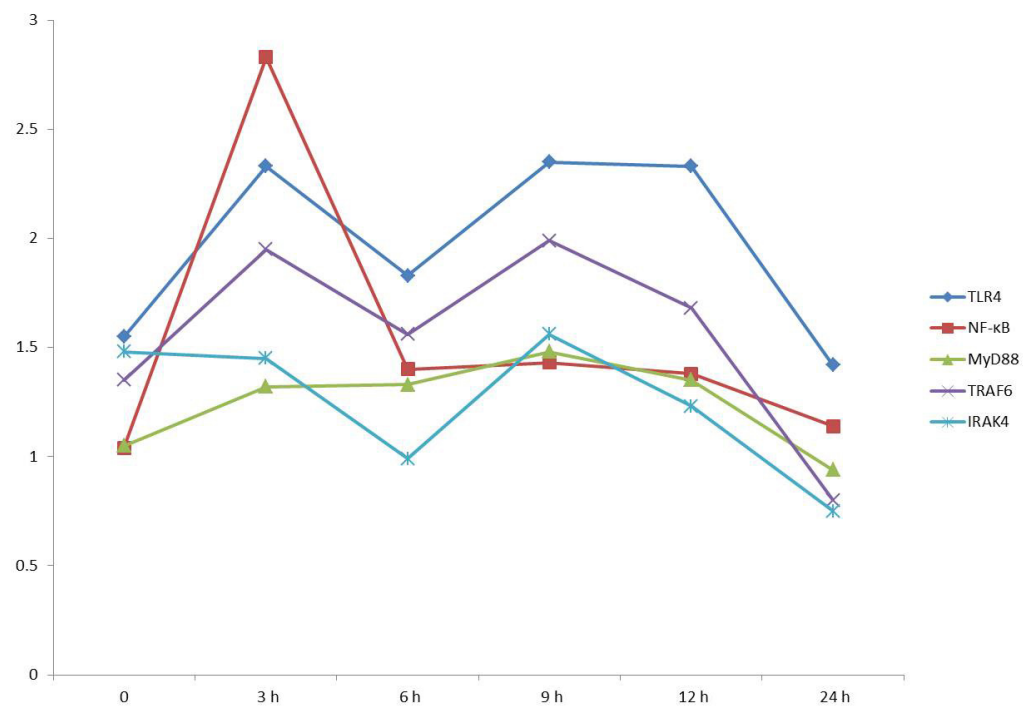

Figure 4. Time-dependent effect of LPS on TLR4 signal molecule expression in hepatocytes. 


\section{Effects of LPS on expression of key lipid metabolism genes in hepatocytes}

As shown in Figures 5 and 6,VLDLR and SCD mRNA increased, while $A C A C a, F A S$, $S R E B P, L X R \alpha$, and $L X R \beta$ mRNA decreased in primary hepatocytes after LPS treatment. The effect of LPS on gene expression depended on the dose and time after treatment. This suggests that LPS can influence the expression of lipid metabolism genes. LPS can attenuate mRNA expression of FA synthesis genes and increase FA transport in dairy cow primary hepatocytes following LPS treatment.

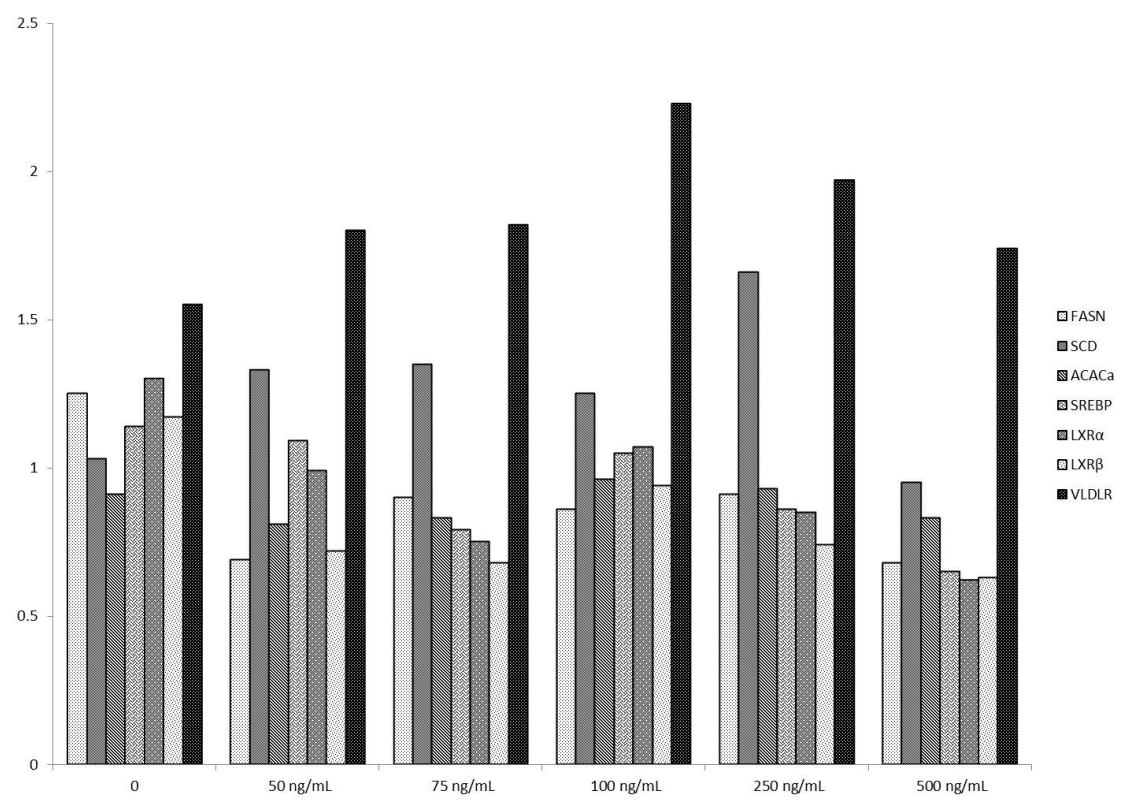

Figure 5. Dose-dependent effect of LPS on expression of key lipid metabolism genes in hepatocytes.

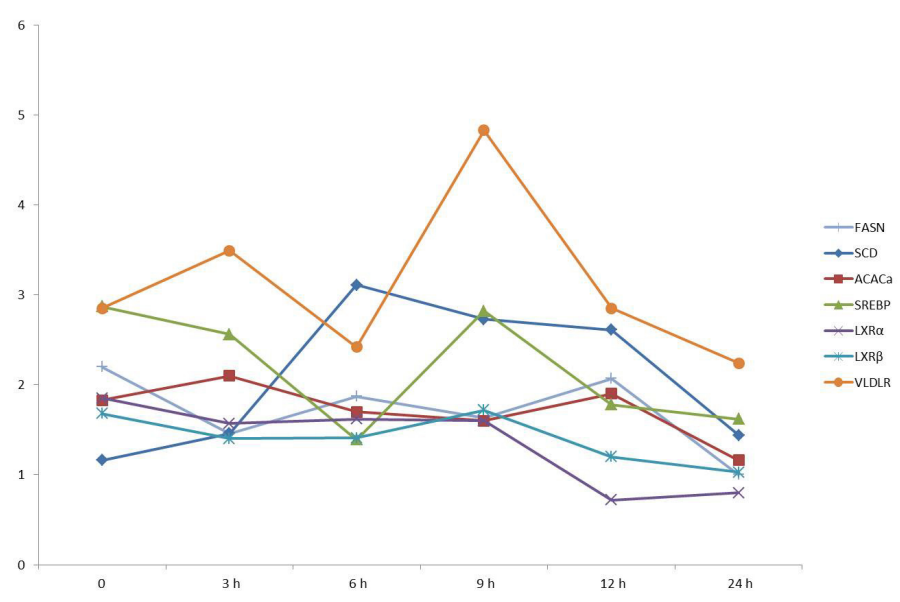

Figure 6. Time-dependent effect of LPS on expression of key lipid metabolism genes in hepatocytes. 


\section{DISCUSSION}

The influence of ruminal acidosis on ruminal microbiology and metabolite production has received considerable attention, but less is known regarding systemic manifestations arising from ruminal acidosis (Brown et al., 2000). It has been increasingly recognized that LPS stimulates the release of proinflammatory cytokines such as TNF- $\alpha$, IL-1, and IL- 6 by liver macrophages, which in turn activate hepatocytic receptors and initiate the synthesis of acute phase proteins (Sweet and Hume, 1996).

TLR4, the receptor for LPS, is important for regulating immune responses and is involved in inflammation-induced cell motility (Philippe et al., 2012). Activation of TLR4 by LPS activates 2 signaling pathways: MyD88-dependent and -independent pathways. The MyD88-dependent pathway requires the recruitment of MyD88, which associates with IRAK and TRAF6. These in turn activate IKB kinase, leading to phosphorylation of transcription factors, such as NF- $\mathrm{kB}$, and then induction of genes encoding cytokines and anti-apoptotic proteins (Park et al., 2005; Kim et al., 2008). The MyD88-independent pathway requires the recruitment of Toll/IL-1-domain-containing adapter-inducing interferon- $\beta$, ultimately activating the transcription factor interferon regulatory factor 3 , and induces the production of interferon- $\gamma$ (Akira et al., 2003a,b).

$\mathrm{NF}-\kappa \mathrm{B}$ is a well-recognized transcription factor that directs the production of proinflammatory chemokines ( $\mathrm{Lu}$ et al., 2008). NF- $\mathrm{KB}$ is sequestered in an inactive form in the cytoplasm by members of the IкB family of inhibitory proteins (Karin and Ben-Neriah, 2000).

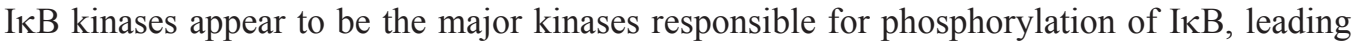
to I $\mathrm{B}$ ubiquitination and degradation, allowing the activation of NF- $\kappa \mathrm{B}$ and production of inflammatory cytokines and chemokines (Baud et al., 1999).

Previous studies have identified the suppressive effects of LPS on key enzymes related to de novo FA synthesis such as FAS and ACAC (Pekala et al., 1983; Lopez-Soriano and Williamson, 1994) in the mammary gland and down-regulation of lipoprotein lipase activity (Khovidhunkit et al., 2004). The latter enzyme plays a key role in clearing circulating triglyceride-rich chylomicrons and VLDL as a host defense mechanism to decrease LPS toxicity (Feingold et al., 1992) and is involved in the uptake of FA for incorporation into milk fat (Merkel et al., 2002).

However, the detailed signaling pathways following LPS binding to TLR4 on SARA have yet to be elucidated. While LPS signaling in macrophages have been extensively studied, its exact role in SARA remains largely unknown.

In the current study, the results of cell cultures showed that hepatocyte changed from irregular triangle shapes to circular shapes (contraction). The number of contracted cells increased with increasing doses of LPS. This suggests that LPS can promote cell contraction and take off the wall, ultimately leading to cell apoptosis. The number of hepatocytes also changed with LPS treatment time. Supplementation of LPS to hepatocytes did not cause cell shrinkage and apoptosis 3-9 $\mathrm{h}$ following LPS treatment. However, hepatocytes shrinkage increased from 12-24 h and apoptosis increased. Irregular triangle cells gradually changed to fusiform, long rod, and then circular shapes. This suggests that LPS plays a promoting role in hepatocyte apoptosis.

Studies of the LPS/TLR4 signaling pathway have mainly focused on human and mouse. Although some studies investigated the interactions between LPS and bovine endometrial cells (EECs) (Herath et al., 2009; Sheldon and Roberts, 2010), the signaling molecules of the TLR4 signaling pathway in bovine hepatocytes have not been well characterized. 
In bovine EECs, TLR4- and MyD88-dependent signaling pathways are essential for the response to LPS (Cronin et al., 2012). Herath et al. (2009) and Fu et al. (2013) also found that expression of TLR4 was up-regulated when bovine EECs were stimulated by LPS. The results showed that the adapter molecule MyD88, transcription factor NF- $\mathrm{KB}$ and cytokine TNF- $\alpha$, IL-1, IL-6, and IL-8 were up-regulated when bovine EECs were challenged with LPS (Fu et al., 2013).

In this study, we also demonstrated that TLR4 and downstream adaptor molecules (MyD88) were associated with IRAK4 and TRAF6, and that the expression of the transcription factors (NF- $\mathrm{kB}$ ) was up-regulated when bovine hepatocytes were stimulated with LPS. The effect of LPS on the expression of these genes was dose- and time-dependent. These results showed that both MyD88-dependent and -independent pathways in TLR4 were activated by LPS in bovine hepatocytes.

In conclusion, we demonstrated that bovine hepatocytes respond to LPS by activating TLR4. The expression of signaling members and inflammatory cytokines of both MyD88dependent and -independent pathways was up-regulated.

Because inflammatory responses are associated with the pathophysiology of many diseases, Cheng et al. (2004) found that conjugated linoleic acid may inhibit LPS-induced inflammatory events in RAW 264.7 macrophages and this inhibitory activity of conjugated linoleic acid, at least in part, occurs through conjugated linoleic acid modulating the NF$\kappa \mathrm{B}$ activation, negatively regulating the expression of inflammatory mediators. The mRNA concentration of genes involved in lipid metabolism and the number of large adipocytes was reduced with LPS pretreatment (Luche et al., 2013). The hexane fraction, rich in FA, inhibited the production of inducible proinflammatory cytokines at the transcriptional level via inactivation of NF-KB (Kim et al., 2013b). Ravindranath et al. (2003) found that endotoxic shock in 10-day-old rat pups induced a systemic inflammatory response with a decrease in FA metabolism, which may contribute to myocardial failure. Chen et al. (2011) showed that a single dose of LPS significantly increased hepatic triglyceride content and caused hepatic lipid accumulation in mice. Further analysis showed that SREBP-1c was activated in LPS-treated mice. In agreement with hepatic SREBP-1c activation, the expression of FAS and ACC, 2 SREBP-1c target genes was significantly up-regulated in the liver of mice injected with LPS (Chen et al., 2011). Intraperitoneal injection of LPS to induce TNF- $\alpha$ expression accelerated hepatic fat accumulation. This study suggests that TNF- $\alpha$, acting downstream of LPS, increased intrahepatic fat deposition by affecting hepatic lipogenetic metabolism involving SREBP-1c (Endo et al., 2007).

LXR is a nuclear receptor that acts as a sterol sensor and metabolic regulator of cholesterol and lipid homeostasis. There is now convincing evidence that LXR is an important modulator of the inflammatory response; however, its mechanism of action remains unclear. Recent reports have demonstrated that LXR of the nuclear receptor family have anti-inflammatory effects on macrophages. LXRs are nuclear receptors that function as important regulators of lipid homeostasis and inflammatory responses. LXRs were found to be expressed in human endothelial cells. While synthetic LXR agonists could blunt the LPS-induced upregulation of adhesion molecules (Morello et al., 2009), LXR activation suppressed the tran-

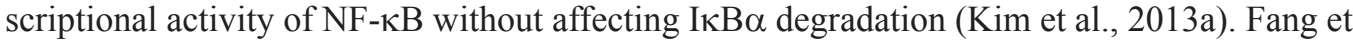
al. (2004) observed marked down-regulation of the nuclear receptors LXR peroxisome proliferator-activated receptor $\alpha$ in rat hepatic gene expression after a single LPS dose. Additionally, the expression of genes encoding lipolytic, antioxidant, and drug- and alcohol-metabolizing 
enzymes was down-regulated. These data suggest that acute LPS treatment induces important early transcription factors and coordinately down-regulates nuclear receptors, resulting in altered expression of a large number of downstream genes (Fang et al., 2004). Canavan et al. (2013) first demonstrated that activation of murine-derived dendritic cells with a specific agonist to LXR enhanced expression of LXR following activation with LPS. Wang et al. (2006) demonstrated that activation of LXR protects against liver injury and dysfunction in a rat model of endotoxemia, in part by exerting an anti-inflammatory effect on Kupffer cells. In this study, the genes VLDLR and SCD mRNA increased, while ACAC $\alpha, F A S, S R E B P, L X R \alpha$, and $L X R \beta$ mRNA decreased in primary hepatocytes after LPS treatment. The effect of LPS on expression of these genes was dose- and time-dependent. This suggests that LPS can influence lipid metabolism-related gene expression. LPS can attenuate mRNA expression of FA synthesis genes and increase FA transport genes in dairy cow primary hepatocytes following LPS treatment.

\section{CONCLUSIONS}

LPS play an important role in promoting hepatocyte apoptosis. The TLR4 signaling pathway mediated by LPS can attenuate mRNA expression of FA synthesis genes and increase FA transport genes in dairy cow primary hepatocytes following LPS treatment.

\section{ACKNOWLEDGMENTS}

Research supported by the Project of National Major Basic Dairy Research "973" Plan (\#2011CB100802) and by the grant of Ministry of Agriculture (\#2011-G35).

\section{REFERENCES}

Akira S, Yamamoto M, Sato S, Hemmi H, et al. (2003a). Role of adaptor TRIF in the MyD88-independent Toll-like receptor signaling pathway. Science 301: 640-643.

Akira S, Yamamoto M, Sato S, Hemmi H, et al. (2003b). TRAM is specifically involved in the Toll-like receptor 4-mediated MyD88-independent signaling pathway. Nat. Immunol. 4: 1144-1150.

Amar J, Burcelin R, Ruidavets JB, Cani PD, et al. (2008). Energy intake is associated with endotoxemia in apparently healthy men. Am. J. Clin. Nutr. 87: 1219-1223.

Ametaj BN, Bradford BJ, Bobe G, Nafikov RA, et al. (2005). Strong relationships between mediators of the acute phase response and fatty liver in dairy cows. Can. J. Anim. Sci. 85: 165-175.

Andersen PH (2003). Bovine endotoxicosis: Some aspects of relevance to production diseases. Acta Vet. Scand. Suppl. 98: 141-155.

Baud V, Liu ZG, Bennett B, Suzuki N, et al. (1999). Signaling by proinflammatory cytokines: oligomerization of TRAF2 and TRAF6 is sufficient for JNK and IKK activation and target gene induction via an amino-terminal effector domain. Genes Dev. 13: 1297-1308.

Brown MS, Krehbiel CR, Galyean ML, Remmenga MD, et al. (2000). Evaluation of models of acute and subacute acidosis on dry matter intake, ruminal fermentation, blood chemistry, and endocrine profiles of beef steers. J. Anim. Sci. 78: 3155-3168.

Canavan M, McCarthy C, Larbi NB, Dowling J, et al. (2013). Activation of liver X receptor suppresses the production of the IL-12 family of cytokines by blocking nuclear translocation of NF-kBp50. Innate Immun. 20: 675-687.

Cani PD, Amar J, Iglesias MA, Poggi M, et al. (2007). Metabolic endotoxemia initiates obesity and insulin resistance. Diabetes 56: 1761-1772.

Cheng WL, Lii CK, Chen HW, Lin TH, et al. (2004). Contribution of conjugated linoleic acid to the suppression of inflammatory responses through the regulation of the NF-kappaB pathway. J Agric. Food Chem. 52: 71-78.

Chen X, Zhang C, Zhao M, Shi CE, et al. (2011). Melatonin alleviates lipopolysaccharide-induced hepatic SREBP-1c activation and lipid accumulation in mice. J. Pineal Res. 51: 416-425. 
Chin AC, Flynn AN, Fedwick JP and Buret AG (2006). The role of caspase-3 in lipopolysaccharide-mediated disruption of intestinal epithelial tight junctions. Can. J. Physiol. Pharmacol. 84: 1043-1050.

Cronin JG, Turner ML, Goetze L, Bryant CE, et al. (2012). Toll like receptor 4 and MYD88-dependent signaling mechanisms of the innate immune system are essential for the response to lipopolysaccharide by epithelial and stromal cells of the bovine endometrium. Biol. Reprod. 86: 51.

Endo M, Masaki T, Seike M and Yoshimatsu H (2007). TNF-alpha induces hepatic steatosis in mice by enhancing gene expression of sterol regulatory element binding protein-1c (SREBP-1c). Exp. Biol. Med. 232: 614-621.

Enemark JMD (2008). The monitoring, prevention and treatment of subacute ruminal acidosis (SARA): a review. Vet. J. 176: 32-43.

Fang C, Yoon S, Tindberg N, Järveläinen HA, et al. (2004). Hepatic expression of multiple acute phase proteins and downregulation of nuclear receptors after acute endotoxin exposure. Biochem. Pharmacol. 67: 1389-1397.

Feingold KR, Staprans I, Memon RA, Moser AH, et al. (1992). Endotoxin rapidly induces changes in lipid metabolism that produce hypertriglyceridemia: Low doses stimulate hepatic triglyceride production while high doses inhibit clearance. J. Lipid Res. 33: 1765-1776.

Fu Y, Liu B, Feng X, Liu Z, et al. (2013). Lipopolysaccharide increases Toll-like receptor 4 and downstream Toll-like receptor signaling molecules expression in bovine endometrial epithelial cells. Vet. Immunol. Immunopathol. 151: 20-27.

Herath S, Lilly ST, Fischer DP, Williams EJ, et al. (2009). Bacterial lipopolysaccharide induces an endocrine switch from prostaglandin F2alpha to prostaglandin E2 in bovine endometrium. Endocrinology 150: 1912-1920.

Karin M and Ben-Neriah Y (2000). Phosphorylation meets ubiquitination: the control of NF-кB activity. Annu. Rev. Immunol. 18: 621-663.

Khafipour E, Li S, Plaizier JC and Krause DO (2009). Rumen microbiome composition determined using two nutritional models of subacute ruminal acidosis. Appl. Environ. Microbiol. 75: 7115-7124.

Khovidhunkit W, Kim MS, Memon RA, Shigenaga JK, et al. (2004). Effects of infection and inflammation on lipid and lipoprotein metabolism: mechanisms and consequences to the host. J. Lipid Res. 45: 1169-1196.

Kim C, Sano Y, Todorova K, Carlson BA, et al. (2008). The kinase p38 alpha serves cell type-specific inflammatory functions in skin injury and coordinates pro- and anti-inflammatory gene expression. Nat. Immunol. 9: 1019-1027.

Kim HJ, Yoon KA, Yoon HJ, Hong JM, et al. (2013a). Liver X receptor activation inhibits osteoclastogenesis by suppressing NF-KB activity and c-Fos induction and prevents inflammatory bone loss in mice. J. Leukoc. Biol. 94: 99-107.

Kim S, Kim JI, Choi JW, Kim M, et al. (2013b). Anti-inflammatory effect of hexane fraction from Myagropsis myagroides ethanolic extract in lipopolysaccharide-stimulated BV-2 microglial cells. J. Pharm. Pharmacol. 65: 895-906.

Lopez-Soriano FJ and Williamson DH (1994). Acute effects of endotoxin (lipopolysaccharide) on tissue lipid metabolism in the lactating rat: The role of delivery of intestinal glucose. Mol. Cell. Biochem. 141: 113-120.

Lu YC, Yeh WC and Ohashi PS (2008). LPS/TLR4 signal transduction pathway. Cytokine 42: 145-151.

Luche E, Cousin B, Garidou L, Serino M, et al. (2013). Metabolic endotoxemia directly increases the proliferation of adipocyte precursors at the onset of metabolic diseases through a CD14-dependent mechanism. Mol. Metab. 2: 281-291.

Merkel M, Eckel RH and Goldberg IJ (2002). Lipoprotein lipase: genetics, lipid uptake, and regulation. J. Lipid Res. 43: 1997-2006.

Morello F, Saglio E, Noghero A, Schiavone D, et al. (2009). LXR-activating oxysterols induce the expression of inflammatory markers in endothelial cells through LXR-independent mechanisms. Atherosclerosis 207: 38-44.

Park JM, Greten FR, Wong A, Westrick RJ, et al. (2005). Signaling pathways and genes that inhibit pathogen-induced macrophage apoptosis-CREB and NF-kappaB as key regulators. Immunity 23: 319-329.

Pekala PH, Kawakami M, Angus CW, Lane MD, et al. (1983). Selective inhibition of synthesis of enzymes for de novo fatty acid biosynthesis by an endotoxin-induced mediator from exudate cells. Proc. Natl. Acad. Sci. U. S. A. 80: 2743-2747.

Philippe L, Alsaleh G, Suffert G, Meyer A, et al. (2012). TLR2 expression is regulated by microRNA miR-19 in rheumatoid fibroblast-like synoviocytes. J. Immunol. 188: 454-461.

Plaizier J, Krause D, Gozho G and Mcbride B (2008). Subacute ruminal acidosis in dairy cows: the physiological causes, incidence and consequences. Vet. J. 176: 21-31.

Ravindranath TM, Goto M, Bakr S and Ramasamy R (2003). LPS-induced changes in myocardial markers in neonatal rats. Biol. Neonate 84: 319-324.

Sheldon IM and Roberts MH (2010). Toll-like receptor 4 mediates the response of epithelial and stromal cells to lipopolysaccharide in the endometrium. PLoS One 5: e12906.

Sweet MJ and Hume DA (1996). Endotoxin signal transduction in macrophages. J. Leukoc. Biol. 60: 8-26.

Tacke F, Luedde T and Trautwein C (2009). Inflammatory pathways in liver homeostasis and liver injury. Clinic. Rev. Allerg. Immunol. 36: 4-12.

Wang YY, Dahle MK, Agren J, Myhre AE, et al. (2006). Activation of the liver X receptor protects against hepatic injury in endotoxemia by suppressing Kupffer cell activation. Shock 25: 141-146. 